\title{
Thermal and hydraulic performance analysis of cylindrical pin fin heat sink with conical perforations
}

\author{
Vishal V. Dhole ${ }^{1 *}$, V. S. Shinde ${ }^{2}$ and S. S. Kore ${ }^{3}$ \\ 1,2Department of mechanical engineering, KJEI's TCOER( Pisoli, Pune), Savitribai Phule Pune University, Pune, India \\ ${ }^{3}$ Department of mechanical engineering, SAE(Kondhwa), Savitribai Phule Pune University, Pune, India \\ Accepted 15 June 2016, Available online 20 June 2016, Special Issue-5 (June 2016)
}

\begin{abstract}
This paper explains the effect of change in perforation geometry and number of perforations of cylindrical pin fin heat sink on heat transfer rate and pressure drop. Heat sinks were tested in rectangular wind tunnel having internal cross section $50 \times 100 \mathrm{~mm}^{2}$. Pin fins were arranged in staged manner. Tests were conducted on different heat sinks at constant heat input of 60W and Reynolds Number 10000-30000. Conical perforations acts like convergent nozzles thus increases the velocity of air passing through them, increased velocity of air raises turbulence over heat sink. Effect of number of conical perforations is studied by changing number of conical perforations. It is found that increase in number of perforation reduces pressure drop and increases Nusselt number. Angle of conical perforations is also varied which plays important role in generating turbulence.
\end{abstract}

Keywords: turbulence, conical perforations, staggered arrangement, pressure drop, convergent nozzle.

\section{Introduction}

The successful working of thermal equipment depends on various factors, majorly cooling or heating of its certain parts. Fins are usually analyzed by assuming uniform heat transfer coefficient model on its surface. However, studies by various investigators revealed that it is not constant, but varies along the fin length. It is mainly because of non-uniform resistance experienced by the fluid flow in the inter fin region. Increasing the heat transfer area heat dissipation rate improves, but increase of resistance to fluid flow causing reduction in heat transfer. In order to dissipate the heat of very high heat flux densities, the required heat sink must often be larger than device. This makes system bulky. To avoid this, area of heat sink exposed to air is increased by introducing perforations to it.

Perforations are nothing but holes of different geometries over lateral surface of the fin. Generally circular holes are used as perforations. These perforations increase area of fin so that it will affect heat transfer by convection. When air jet strikes surface of circular solid fin, wakes are generated behind the fin. In this region air movement is negligible as it is perfectly behind obstacle (fin) causes formation of hot zones behind fins which lowers heat transfer rate. Use of perforations on the lateral surface area will increase number of wakes and reshape aerodynamic structure of flow. The air which is behind the fins is

*Corresponding author: Vishal V. Dhole moved by new air jets formed due to perforations, and hence increases heat transfer rate.

Circular, elliptical and square heat sinks with staggered and inline configurations were tested along with two plate heat sinks. It is found that elliptical heat sinks gives slightly better performance than circular fins (Kai-Shing Yang et al 2007). Performance of pin fins with different cross sections is evaluated with the help of simulation. For FCC (first comparison criteria) in staggered arrangement the Circular profile perform better than all other pin cross section and for SCC (second comparison criteria) in staggered arrangement the Elliptic profile perform better than all other pin cross section (N.Sahiti et al, 2006). Compared plate fin and pin fin heat sink, based on volume averaging approach for predicting the pressure drop and thermal resistance (Dong-Kwon Kim et al 2009). Performance analysis of plate fins and circular, elliptical, square pin fin arrays shows. At lower values of Pumping power and Pressure drop, elliptical fins offer high performance while at higher values Circular fins work best (Denpong Soodphakdee et al, 2001). Plate fin, Strip fin and Pin fin (circular and square) configurations were tested for variation in height of fins, variation of width of tunnel, keeping width of array constant, variation of height of tunnel keeping height of array constant (Hans Jonsson et al 2001). Effects of side and top bypass on the hydraulic and thermal performances of a cylindrical pin-fin heat sink will be investigated in laminar forced convection, and it is found that for better thermal performance pressure 
drop must be compensated (W. A. Khan et al 2006). Heat transfer coefficients for staggered array are higher than in-line array whereas high pressure drop is observed for staggered arrangements than In-line arrangement (E.M.Sparrow et al1980). The use of perforated square fin increases the heat transfer coefficient. It is seen that perforated fins Staggered arrangement perform better than Inline arrangement in terms of heat transfer ( A.A. Kanaskar et al.,). The effects of inter fin spacing, shroud clearance, and missing pin on the heat transfer from cylindrical pin fins arranged in staggered and in-line arrays has been studied. (B. A. Jubran et al. 1993). Stream wise and Span wise distances were optimized for staggered and in-line arrangements of the pin fin. For Inline arrangement Stream wise (Sy/L) and Span wise (Sx/Wb) distances are found to be 0.173 and 0.135 respectively. For Staggered arrangement Stream wise (Sy/L) and Span wise (Sx/Wb) distances are found to be 0.1 and 0.19 respectively ( $M$. Tahat et al 2000). Effect of Clearance ratio $(\mathrm{C} / \mathrm{H})$ and Inter Fin Spacing (Sy/D) for cylindrical cross-sectional perforated pin fins were investigated. It is found that maximum heat transfer rate and minimum friction factor was observed at 42,000 Reynolds No, 3.417 pitch and $50 \mathrm{~mm}$ fin height (Amol B. Dhumne et al 2013). The effects of the number of perforations and the diameter of perforation on each pin are also studied. It has been conclude that perforated pin fin array performs better than the solid pins.. It is found that, the balance between the perforation number and diameter should be carefully taken into consideration. Maximum system performance may be obtained with perforated pin fins when ratio of Diameter of perforation to the Diameter of pin fin will be equal to 0.375 (Swee-Boon Chin et al., 2013).It is found by experimental and CFD investigation that fins with five perforations are shown to have $11 \%$ larger Nusselt Number than for corresponding solid fin case (Amer Al-Damook et al 2015). The combined effect of vertical perforations and horizontal perforations on heat transfer rate and pressure drop has been investigated when air is impinged on heat sink from top side. It is observed that heat transfer rate will increase for sink having $\mathrm{N}=5$ and horizontal perforation diameter $\mathrm{Dp}=3 \mathrm{~mm}$ with increase in vertical perforation diameter up to $3 \mathrm{~mm}$ (Ji Jinn Foo et al 2012). Nusselt number of pin with horizontal/vertical perforation are about $11 \%$ higher than those for solid pin fins and with horizontal / vertical / lateral perforation are about $21 \%$ higher than those for solid pin fin (Ali Shakir Baqir et al 2014).

\section{Experimental setup}

Experimental setup consists of rectangular wind tunnel in which heat sink is to be tested. Wind tunnel is made up of $6 \mathrm{~mm}$ thick epoxy resin material (thermal conductivity $=0.29 \mathrm{~W} / \mathrm{mK}$ ) having height $50 \mathrm{~mm}$, width $100 \mathrm{~mm}$. Length of wind tunnel is $1045 \mathrm{~mm}$ which is divided into 3 parts viz. entrance length $745 \mathrm{~mm}$, test section $110 \mathrm{~mm}$ and $195 \mathrm{~mm}$ downstream length .Heat sink is fitted at test section part. This setup was operated in exhaust mode and positioned horizontally. Blower (1HP Atul, Rajkot) is used to throw air on heat sink at varying velocity (Max $12 \mathrm{~m} / \mathrm{s}$ ). Velocity of air is adjusted with the help of gate valve attached next to the blower. Flow rate of air is measured by orifice plate assembly fitted in between blower and wind channel. A transition element is used to convert flow from circular pipe to rectangular wind tunnel.

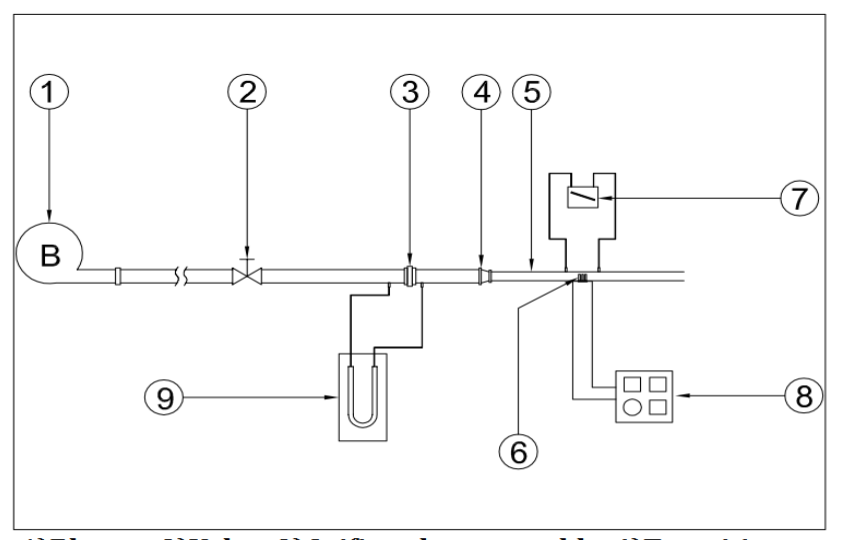

1)Blower, 2)Valve, 3)Orifice plate assembly, 4)Transition element, 5)Wind tunnel, 6)Heat sink(test peice) 7) Inclined manometer, 8)Electric panel, 9)U tube manometer.

Fig.1 Schematic diagram of the experimental setup

Heat sink is fabricated from aluminum alloy (A5083P, thermal conductivity, $\mathrm{K}=168 \mathrm{~W} / \mathrm{mK}$ ) which is installed at test section of wind tunnel. Each pin fin consists of 8 $\mathrm{mm}$ diameter and $56 \mathrm{~mm}$ length.

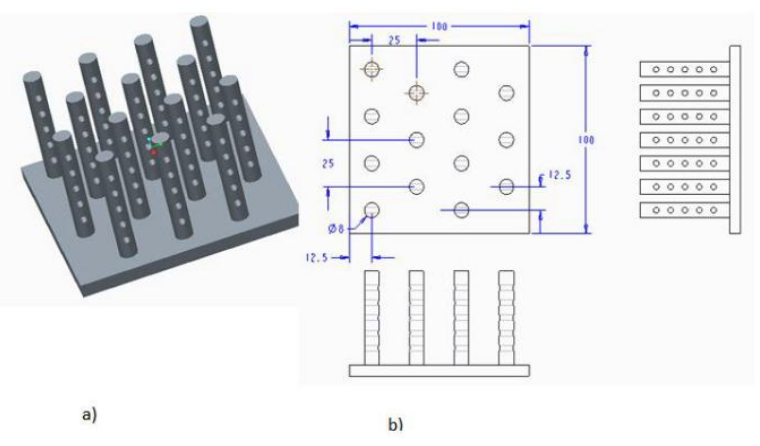

Fig.2 a) 3D model, and b) 2D drawing of heat sink with number of perforations, $\mathrm{N}=5$.

Total 14 numbers of pin fins are press fitted on base plate of $6 \mathrm{~mm}$ thickness having dimension $100 \mathrm{~mm} \times$ $100 \mathrm{~mm}$. Pin fins are arranged in staggered arrangement for all heat sinks to be tested. Customized drilling tools are used for making conical perforations on the lateral surface of pin. Holes are arranged in the direction of air flow in case of perforated pin fin heat sink and in case of conical perforations, larger diameter of perforation is always kept on the upstream side. Thermo foil plate heater having same dimensions as that of base plate is placed exactly below base plate of heat sink, which will mimic the heat dissipated by 
electronic component. K-type thermocouples are used to measure temperatures at inlet, outlet and base plate. An electric panel is used to show different temperatures and to control voltage supplied to heater. Pressure tapings are provided to measure pressure drop across the heat sink measured by inclined manometer.

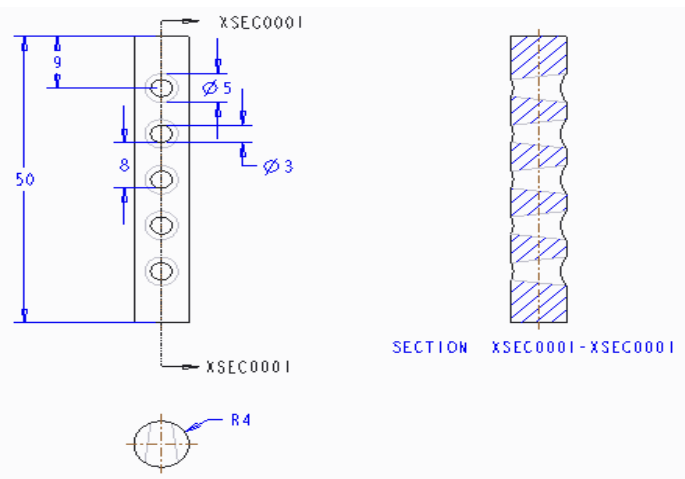

Fig.3 Detailed drawing of pin fin with $(\mathrm{N}=5)$ conical perforations.

\section{Data Processing}

Heat is transferred to heat sink from square plate heater by conduction as it has direct contact with heater plate. During this process, there are some heat losses by conduction and radiation. This can be written in analytical form as,

$Q_{\text {ele }}=Q_{\text {cond }}+Q_{\text {conv }}+Q_{\text {rad }}$

So net electrical energy supplied to heat is,

$\mathrm{Q}_{\text {net }}=\mathrm{Q}_{\text {ele }}-\mathrm{Q}_{\text {loss }}$

$\mathrm{Q}_{\text {loss }}=\mathrm{Q}_{\text {downside cond }}+\mathrm{Q}_{\text {axial cond }}+\mathrm{Q}_{\text {rad }}$.

Most of the heat losses are from downside of heater, where firebrick insulation is provided

Heat loss by downside conduction is given by equation, $Q_{\text {downside cond }}=\frac{\text { A. } \mathrm{K}_{\text {ins }}}{\Delta \mathrm{X}} . \Delta \mathrm{T}_{\text {ins }}$, where $\Delta \mathrm{X}$ is insulation thickness, $\Delta \mathrm{T}_{\text {ins }}$ is temperature difference across insulation.

Radiation heat losses are calculated by equation, $\mathrm{Q}_{\text {rad }}=\sigma \mathrm{A}\left(\mathrm{T}_{\mathrm{b}}^{4}-\mathrm{T}_{\mathrm{atm}}^{4}\right)$ and found to be $0.5 \%$ of total heat loss.

Therefore, At steady state, $Q_{\text {net }}=Q_{\text {conv }}$ i.e. heat transfer rate from heat sink by convection.

Equation for Nusselt Number can be given as,

$$
\mathrm{Nu}=\frac{\mathrm{Q}_{\text {conv }} \cdot \mathrm{D}_{\mathrm{h}}}{\mathrm{A}_{\mathrm{s}} \cdot \mathrm{K}_{\mathrm{air}}\left\{\mathrm{T}_{\mathrm{b}}-\left(\frac{\mathrm{T}_{\text {in }}+\mathrm{T}_{\text {out }}}{2}\right)\right\}}
$$

This $\mathrm{Nu}$ is calculated on the basis of projected area which will indicate the effect on heat transfer rate due to disturbances in the flow and change in surface area due to presence of perforations.

Pressure Drop, $\Delta \mathrm{P}=\left(\mathrm{P}_{2}-\mathrm{P}_{1}\right)$.

Friction factor, $\mathrm{f}=\frac{2 \rho \Delta \mathrm{P}}{\frac{\mathrm{L}}{\mathrm{D}_{\mathrm{h}}}\left(\frac{\mathrm{m}}{\mathrm{A}_{\mathrm{ff}}}\right)^{2}}$.
Total surface area of solid fin,

$\mathrm{A}_{\text {solid }}=\mathrm{WL}+\mathrm{N}(\pi \mathrm{DH})$.

Total surface area of fin with circular perforation,

$A_{\text {pcir }}=W L+n\left\{\pi D\left(H-\frac{D}{4}\right)+\pi d N\left(D-\frac{d}{2}\right)\right\}$.

Total surface area of fin with conical perforation,

$A_{\text {Pcone }}=W L+\pi n\left\{\left[D\left(H-\frac{D}{4}\right)\right]+N\left[(R L-r l)-\left(R^{2}-\right.\right.\right.$ $\left.\left.\left.\mathrm{r}^{2}\right)\right]\right\}$.

Porosity of fin,

For circular perforation,

$\phi=\frac{N\left(\frac{\pi d_{p}^{2}}{2}+\pi D d_{p}\right)}{\pi D H}$.

2) For Conical perforations,

$\phi_{\text {conical }}=\frac{\mathrm{N} \pi\left\{\left(\mathrm{R}^{2}+\mathrm{r}^{2}\right)+(\mathrm{RL}-\mathrm{rl})\right.}{\pi \mathrm{DH}}$.

The values of thermophysical properties air were calculated at bulk mean temperature of air, which is

Bulk mean temperature, $\mathrm{T}_{\mathrm{bm}}=\left(\frac{\mathrm{T}_{\mathrm{in}}+\mathrm{T}_{\mathrm{out}}}{2}\right)$.

\section{Results and Discussion}

\section{1) Effect of number of perforations on Nusselt Number}

Figure 4 shows the effect of variation in number of conical perforations on heat transfer rate as a function of Reynolds number. It is observed that The Nusselt numbers increases with increase in Reynolds number. Increase number of conical perforations on pin fin increases the area exposed to air for heat transfer. This results into increase in Nusselt number. Hence increase in porosity of pin fin results in heat transfer enhancement. Heat sinks with conical perforations gives better reults for heat transfer when compared with solid fin heat sink.

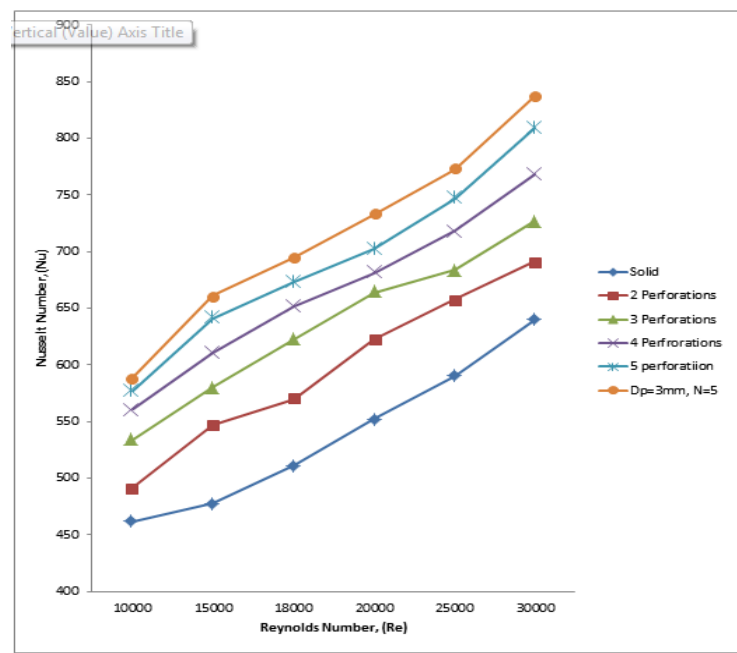

Fig.4 Nusselt number as a function of equivalent Reynolds number and Number of conical perforations

\section{2) Effect of number of perforations on Pressure drop}

Figure 5 shows effect of number of perforations on pressure drop relative to Reynolds number. Results 
shows pressure drop increases with increase in Reynolds number. Solid fins gives highest pressure drop when compared with perforated fins all values of Reynolds number, because it provide more blockage to air flow. Use of perforated fins reduces pumping power hence reduction in operating cost.

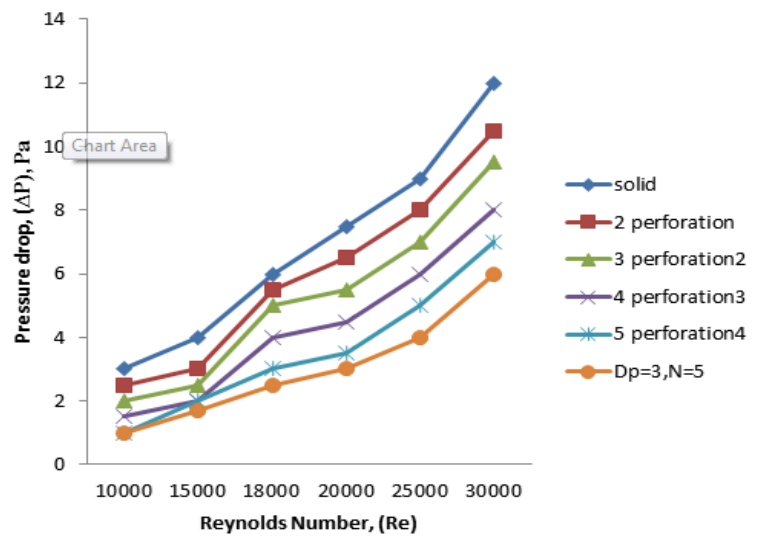

Fig. 5 Pressure drop as a function of equivalent Reynolds number and Number of conical perforations

\section{3) Effect cone angle of perforations on Nusselt number}

Figure 6 shows the behavior Nusselt number as a function of Reynolds and cone angle of conical perforations at constant heat input. Heat sink with dimensions of pin fin perforation $4 * 2$ gives maximum value of Nusselt number. Heat sink having circular perforations gives middle range value of Nusselt number.

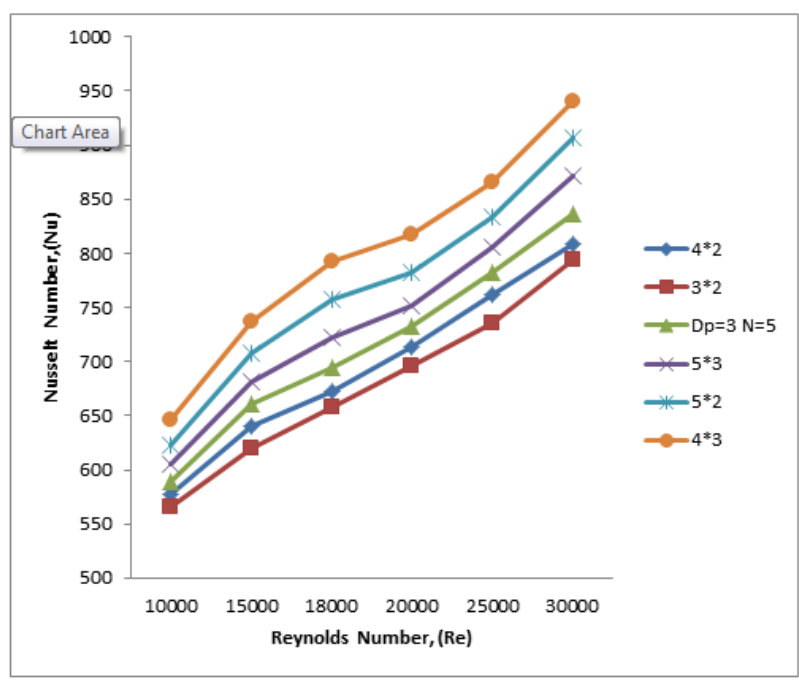

Fig. 6 Nusselt number as a function of equivalent Reynolds number and Cone angle of conical perforation

The performance of heat sinks is highly influenced by area of conical perforation and cone angle of conical perforation. As taking higher values of area of conical perforation gives reduction in vertical heat transfer rate, which shows adverse effects on heat transfer rate by convection. So, optimum values of area of conical perforation and cone angle of perforation should be selected to give highest value of Nusselt number.

\section{Conclusions}

The forced convective heat transfer from cylindrical pin fin heat sink in rectangular wind tunnel was investigated experimentally. The effects of flow and geometrical parameters on heat transfer and pressure drop were determined at constant heat input of $60 \mathrm{~W}$. The conclusions of the study are:

1) Nusselt number increases with increase Number of conical perforations. So porous pin fin gives higher values of heat transfer coefficient.

2) Pressure drop across heat sink is due to blockade provided by pin fins to the air flow. More the resistance to the air flow, higher the pressure drop which increases pumping power required to throw air on heat sink.

3) Increase in number of conical perforations results in decreases the pressure drop across heat sink. So, heat sink with more number of conical perforation reduces pumping power thus reduction in operation cost.

4) Change in Cone angle of conical perforation reshapes aerodynamic structure of flow. Variation of cone angle effects in change in perforation area of pin fin. It also changes velocity of air passing through perforated area and influences turbulence.

5) Effect of changes in conical perforation can be precisely studied by simulation technique as experimental analysis has its own limitations for finding values of velocity and amount of turbulence at different point.

\section{References}

Kai-Shing Yang, Wei-Hsin Chu, Ing-Yong Chen and Chi-Chuan Wang, (2007), A Comparative Study of The Airside Performance of Heat Sinks having Pin Fin Configurations , International Journal of Heat and Mass Transfer, 50, 46614667.

N. Sahiti, A. Lemouedde, D. Stojkovic, F. Durst and E.Franz b, (2006), Performance Comparison of Pin Fin in-duct Flow Arrays with Various Pin Cross-sections, Applied Thermal Engineering, 26, 1176-1192.

Royston Marlon Mendonca, Sai Sharan Yalamarty, (2015), Numerical analysis of heat sinks for LED lighting modules, Volume: 04, 142-150.

Dong-Kwon Kim, Sung Jin Kim, Jin-Kwon Bae, (2009), Comparison of thermal performance of plate fin and pin fin heat sinks subject to an impinging flow. International Journal of Heat and Mass Transfer 52, 3510-3517

Denpong Soodphakdee, Masud Behnia, David Copeland, ( 2001), A comparison of fin geometries for heat sinks in laminar forced convection: Part I-Round, Elliptical, and Plate fins in Staggered and In-Line configurations, The 
International Journal of Microcircuits and Electronic Packaging, Volume 24, First Quarter, (ISSN 1063-1674)

Hans Jonsson and Bahram Moshfegh, (2001), Modeling of the thermal hydraulic performance of plate fin, strip fin, and pin fin heat sinks-Influence of flow bypass, IEEE transactions on components and packaging technologies, Vol 24,No.2, 142-149.

E.M.Sparrow, J.W. Ramsay, C.A.C.Altemani,( 1980) Experiments on In-Line pin fin arrays and performance comparisons with Staggered array, Journal of Heat Transfer,, Vol. 102, 44-50.

R.A.Wirtz, D.M.Colban, (1996), Comparison of cooling performance of Staggered and In-Line arrays of electronic packages, Journal of Electronic Packaging, Vol. 118, 27-30

A.A. Kanaskar, V.M. Kriplani and P.V. Walke, "Experimental Analysis of Heat Transfer Enhancement of Perforated Square Fins in a Duct", International Journal of Latest Trends in Engineering Science and Technology, Volume-2, Issue I, ISSN:2055-530X.

B. A. Jubran, M. A. Hamdan, (1993), Enhanced heat transfer, Missing fin, and Optimization for cylindrical pin fin array, Journal of Heat Transfer, Vol. 115, 576-583.

Kadir Bilen, Ugur Akyol, Sinan Yapici, (2001), Heat transfer and friction correlations and thermal performance analysis for a finned surface, Energy Conversion and Management 42,1071-1083.

M. Tahat, Z.H. Kodah, B.A. Jarrah, SD Probert, (2000), Heat Transfer from pin fin arrays experiencing forced convection, Applied Energy 67,419-442.

W.A. Khan, J.R. Chulham(2006), Effect of bypass on overall performance of pin fin heat sink, AIAA/ASME Joint thermo physics and heat transfer conference, AIAA 2006-3604113.
Ugur Akyol, Kadir Bilen, (2006), Heat transfer and themal performance analysis of a surface with hollow rectangular fins, Applied Thermal Engineering, 26 ,209-216.

Amol B. Dhumne and Hemant S. Farkade, (2013), Heat Transfer Analysis of Cylindrical Perforated Fins in Staggered Arrangements, International Journal of Innovative Technology and Exploring Engineering,Volume2,Issue-5, ISSN:2278-3075.

Swee-Boon Chin, Ji-Jinn Foo, (2013), Forced convective heat transfer enhancement with perforated pin fins, Heat and Mass Transfer, 49, 1447-1458.

Amer Al-Damook, N.Kapoor, J.L.Summers, H.M.Thompson, (2015), An experimental and computational investigation of thermal air flows through perforated fins, Applied Thermal engineering, 89, 365-376

Ji Jinn Foo and Chee Seng Tan, (2012), Heat Transfer Enhancement with Perforated Pin Fins Subject to Impinging Flow, Int. J. of Mechanical Computational and Manufacturing Research, Vol. 1. No. 2, 56-61, ISSN: 2301 4148

Ali Shakir Baqir, Ahmed Qasim and Anmar Adnan, (2014), Experimental Study for Staggered Perforated Array of Pins like Fins in a Rectangular Cross flow, The Iraqi Journal For Mechanical and Material Engineering, Vol.14, No 2,261275.

Ji-Jinn Foo, Shung-Yuh Pui, Yin-Ling Lai and Swee-Boon Chin, (2012), Forced Convective Heat Transfer Enhancement with Perforated Pin Fins Subject to an Impinging Flow, Vol. 5, No. 1, 29-40. 